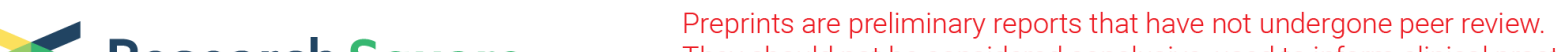 Research Square
They should not be considered conclusive, used to inform clinical practice,
or referenced by the media as validated information.
}

\section{Metabolic, physiological and anatomical responses of soybean plants under water deficit and high temperature condition}

\section{Roberto Gomes Vital}

Federal Institute of Science and Technology Goiano - Campus Rio Verde

Caroline Müller

Federal Institute of Science and Technology Goiano - Campus Rio Verde

Francisco Bruno Silva Freire

Federal University of Ceará

\section{Fábia Barbosa Silva}

Federal Institute of Science and Technology Goiano - Campus Rio Verde

\section{Priscila Ferreira Batista}

Federal Institute of Science and Technology Goiano - Campus Rio Verde

\section{David Fuentes}

The University of Sydney

\section{Arthur Almeida Rodrigues}

Federal Institute of Science and Technology Goiano - Campus Rio Verde

\section{Luciana Minervina Freitas Moura}

Federal Institute of Science and Technology Goiano - Campus Rio Verde

\section{Danilo Menezes Daloso}

Federal University of Ceará

\section{Adinan Alves Silva}

Federal Institute of Science and Technology Goiano - Campus Rio Verde

Andrew Merchant

The University of Sydney

Alan Carlos Costa ( $\sim$ alan.costa@ifgoiano.edu.br)

Federal Institute of Science and Technology Goiano - Campus Rio Verde

\section{Research Article}

Keywords: Gas exchange, Glycine max, heat stress, metabolic networks, plant systems biology

Posted Date: February 11th, 2022

DOI: https://doi.org/10.21203/rs.3.rs-1317816/v1 
License: (c) (i) This work is licensed under a Creative Commons Attribution 4.0 International License. Read Full License 


\section{Abstract}

Water deficit (WD) combined with high temperature $(\mathrm{HT})$ is the major factor limiting agricultural worldwide, and it is predicted to become worse according to current climate change scenario. It is thus important to understand how current cultivated crops respond to these stress conditions. Here we investigated how four soybean cultivars respond to WD and HT isolated or in combination at metabolic, physiological, and anatomical levels. The WD+HT increased the level of stress in soybean plants, when compared to plants under well-watered (WW), WD or HT conditions. WD+HT exacerbate the increases in ascorbate peroxidase activity, which was associated with greater photosynthetic rate in two cultivars under $\mathrm{WD}+\mathrm{HT}$. The metabolic responses to $\mathrm{WD}+\mathrm{HT}$ diverge substantially from plants under WW, WD or $\mathrm{HT}$ conditions. Myo-inositol and maltose were identified as WD+HT biomarkers and were connected to subnetworks composed by catalase, amino acids and both root and leaf osmotic potentials. Correlationbased network analyses highlight that the network heterogeneity increased and a higher integration among metabolic, physiological and morphological nodes is observed under stress conditions. Beyond unveiling biochemical and metabolic WD+HT biomarkers, our results collectively highlight that the mechanisms behind the acclimation to WD+HT cannot be understood by investigating WD or HT stress separately.

\section{Introduction}

Soybean (Glycine max (L.) Merr.) is an economically important crop worldwide. Breeding programs over the last century have resulted in highly productive soybean cultivars that are adapted to distinct environmental conditions. However, increasing climate instability, which is predicted to directly alter both rainfall and environmental temperature, have raised concern regarding the maintenance of soybean crop yield ${ }^{1-3}$. Periodic temperature increases at critical stages of soybean development associated with lower rainfall have been reported in various continents. In Brazil, one of the major soybean productors, the reduced yield of soybean cultivated in the Central-West region in 2018/2019 was associated with an increase of up to $3^{\circ} \mathrm{C}$ above of the average temperature normally found in this area 4,5 . This highlights how climate change may affect soybean production in tropical areas, which has clear impacts worldwide. Thus, understanding the mechanisms by which plants acclimate to water deficit (WD) combined with high temperature (HT) is crucial for identifying stress tolerant cultivars and to pave the way for obtaining soybean cultivars with higher productivity under combined WD and HT stress conditions.

Plant stress responses involve the modulation of a complex network that leads to molecular, physiological and/or morphological alterations in the plant according to the intensity of the stress level 6,7 . In general, plant acclimation to WD initially includes the activation of mechanisms such as abscisic acid-mediated stomatal closure and osmotic adjustment through the accumulation of several osmoprotective compounds, such as sugars, sugar-alcohols and amino acids ${ }^{8-12}$. The combination of these and several other hormonals, hydraulic, signaling and antioxidant mechanisms triggered by WD are important to minimize deleterious effects caused by the stress and to maintain cell turgor and plant 
growth ${ }^{13-15}$. Under HT conditions, sucrose accumulation has also been described as important component of osmotic adjustment ${ }^{16}$. Furthermore, it has been shown that amphiphilic molecules such as proline and sugar alcohols act in the stabilization of cellular structures protecting cell membranes affected by heat stress ${ }^{17}$. It seems likely therefore that plant responses to heat stress have certain similarities with drought. However, drought is commonly associated to HT under field condition and evidence highlights that the metabolic responses to the combination of both stresses is substantially different from drought or heat stress separately ${ }^{18}$. It is thus important to investigate both stresses combined to unveil which mechanisms confer higher plasticity or higher tolerance to the combination of WD and HT stresses.

Soil water availability is generally reduced as temperature increases. Under these conditions, stomatal closure is an important response to avoid excessive water loss, but as consequence this reduces $\mathrm{CO}_{2}$ fixation mediated by ribulose-1,5-bisphosphate carboxylase/oxygenase activity ${ }^{19}$. Additionally, thermal stress reduces $\mathrm{CO}_{2}$ solubility and increase the permeability of the thylakoid membranes, favoring $\mathrm{O}_{2}$ fixation and thus photorespiration and destabilizing the photosynthetic electron transport chain ${ }^{20}$. This leads to an energy imbalance promoted by excessive light absorption, which increase the production of oxidizing compounds such as reactive oxygen species (ROS), causing oxidative damage to lipids and membrane proteins ${ }^{21}$. As a defense mechanism, plants acclimate to combined WD and HT activating enzymatic mechanisms of the antioxidant defense system to remove excess of ROS. This includes increase in the activity of superoxide dismutase (SOD), catalase (CAT), ascorbate peroxidase (APX) and peroxidase (POD) ${ }^{22}$ as well as the activation of non-enzymatic ROS scavenging mechanisms such as the synthesis of ascorbate ${ }^{23}$ and flavonoids/anthocyanins ${ }^{24}$. These mechanisms have been highlighted as important to the tolerance of $\mathrm{HT}$ and WD by plants ${ }^{25}$. For instance, increased antioxidant enzyme activity was observed in the WD tolerant canola variety ${ }^{26}$ and in heat stress-tolerant chicken grass plants 27. However, it is still unclear whether the antioxidant system is an active response or passive consequence of soybean acclimation to WD+HT.

Several examples in the literature highlight that identifying drought stress tolerant genotypes is commonly achieved at the expense of photosynthetic rate, growth and/or yield under non-adverse and/or stress conditions ${ }^{28-30}$. However, given current and projected demand for food production, genotypes that maintain high photosynthetic performance under the combination of WD and HT without severe penalties in yield under both non-adverse and stressed conditions are desirable ${ }^{31}$. The major challenge for plant scientists is thus to fully comprehend the trade-off among yield and (a)biotic stress tolerance in order to successfully manipulate plant metabolism toward simultaneous plant growth and stress tolerance improvements ${ }^{32,33}$. This challenge is higher when the combination of WD and HT are considered, given that the effects of these stresses combined can exacerbate damage to metabolism, reducing crop growth and yield ${ }^{34,35}$. Furthermore, studies integrating physiological, morphoanatomical and metabolic responses of plants exposed to combined stress are scarce, which hampers our understanding concerning the modulation of the entire plant network under WD+HT. In order to address this gap, we 
used an integrative approach to investigate physiological, morphoanatomical and metabolic responses of four soybean cultivars subjected to WD and HT in isolated or combined conditions. The results are discussed in the context on the importance in considering investigating WD and HT combined to unveil the mechanisms by which plants acclimate under these stress conditions.

\section{Methods}

Experimental conditions and experimental design. Soybean cultivars NS7209 IPRO (Nidera Seeds, São Paulo, Brazil), NS7011 IPRO (Nidera Seeds, São Paulo, Brazil), Desafio 8473 RSF (Brasmax Seeds, Passo Fundo, Brazil) and 7739 M IPRO (Monsoy Seeds, São Paulo, Brazil) were grown in growth chambers (Instalafrio, Pinhais, PR, Brazil) with controlled conditions of relative humidity ( $65 \%)$, irradiance ( 650 $\left.\mu \mathrm{mol} \mathrm{m} \mathrm{m}^{-2} \mathrm{~s}^{-1}\right)$ and temperature $\left(25 / 20^{\circ} \mathrm{C}\right.$, day/night). The four soybean cultivars were selected due to their characteristics of high productivity, and wide cultivation in Brazil.

Plants were grown in polyethylene pots containing $8 \mathrm{Kg}$ of substrate prepared from Red Latosol (LVdf) soil and sand (2:1). The subtrate used had the following composition: $\mathrm{pH} \mathrm{CaCl}_{2}-5.6 ; \mathrm{P}-0.7 \mathrm{mg} \mathrm{dm}^{-3} ; \mathrm{K}$ $-13.0 \mathrm{mg} \mathrm{dm}^{-3} ; \mathrm{Ca}-1.54 \mathrm{cmol}_{\mathrm{C}} \mathrm{dm}^{-3} ; \mathrm{Mg}-0.22 \mathrm{cmol}_{\mathrm{C}} \mathrm{dm}^{-3} ; \mathrm{Al}-0.05 \mathrm{cmol}_{\mathrm{C}} \mathrm{dm}^{-3} ; \mathrm{H}^{+} \mathrm{Al}-1.3 \mathrm{cmol}_{\mathrm{C}}$ $\mathrm{dm}^{-3} ; \mathrm{S}-3.5 \mathrm{mg} \mathrm{dm}^{-3} ; \mathrm{B}-0.8 \mathrm{mg} \mathrm{dm}{ }^{-3} ; \mathrm{Cu}-1.0 \mathrm{mg} \mathrm{dm}^{-3} ; \mathrm{Fe}-37.8 \mathrm{mg} \mathrm{dm}^{-3} ; \mathrm{Mn}-13.2 \mathrm{mg} \mathrm{dm}^{-3} ; \mathrm{Zn}$ $-0.1 \mathrm{mg} \mathrm{dm}{ }^{-3} ; \mathrm{Na}-6.0 \mathrm{mg} \mathrm{dm}{ }^{-3} ; \mathrm{SB}-58 \%$; CTC $-3.1 \mathrm{cmol}_{\mathrm{c}} \mathrm{dm}^{-3}$; organic matter $-109 \%$. Based on these characteristics, liming was performed using dolomitic limestone, increasing the base saturation to $60 \%$. The plants were fertilized with $0.2 \mathrm{~g} \mathrm{dm}^{-3}$ of mono-ammonium phosphate (MAP), $0.16 \mathrm{~g} \mathrm{dm}^{-3}$ of potassium chloride $(\mathrm{KCl}), 0.18 \mathrm{~g} \mathrm{dm}^{-3}$ of potassium sulphate $\left(\mathrm{K}_{2} \mathrm{SO}_{4}\right), 0.2 \mathrm{~g} \mathrm{dm}^{-3}$ of urea $\left(\mathrm{CH}_{4} \mathrm{~N}_{2} \mathrm{O}\right)$ and $0.026 \mathrm{~g} \mathrm{dm}^{-3}$ of zinc sulfate $\left(\mathrm{ZnSO}_{4}\right)$, according to the recommendation for Cerrado soils in which soybean are cultivated ${ }^{86}$. Two plants were grown per pot, representing one experimental unit.

Treatments consisted of a combination of two water replacements ( 100 and $40 \%$ of soil holding water capacity, HWC) and two temperatures $\left(25 / 20^{\circ} \mathrm{C}\right.$ or $40 / 25^{\circ} \mathrm{C}$, day/night) imposed at the V3 development stage. The control of soil moisture in the pots was done using the gravimetric method, by replacing the water lost by evapotranspiration in a daily basis. The high temperature (HT) was imposed when the plants reached the water deficit by gradually increasing from $25^{\circ} \mathrm{C}$ at $10 \mathrm{~h}$ until reaching $40{ }^{\circ} \mathrm{C} \pm 0.5^{\circ} \mathrm{C}$ at 11:30 h, maintained for five hours. After this period, the temperature gradually decreased until it returned to $25^{\circ} \mathrm{C}$ at $18: 30 \mathrm{~h}$, repeating this cycle in the following day. Thermal treatments were imposed for an 8-day period, during which time physiological, biochemical, metabolic and morphoanatomical evaluations were made.

The experimental design was arranged in randomized blocks, in a factorial design with two water replacements $(100 \%$ and $40 \% \mathrm{HWC})$ and two temperatures $\left(25^{\circ} \mathrm{C}\right.$ and $\left.40^{\circ} \mathrm{C}\right)$, with five replicates.

Water relations and leaf temperature. Leaf water potential $\left(\Psi_{\mathrm{w}(\mathrm{am})}\right)$ was measured using a Scholander pressure chamber (Model 3005-1412, Soilmoisture Equipment Corp., Goleta, CA, USA). Osmotic leaf 
$\left(\Psi_{\text {s(leaf })}\right)$ and root $\left(\Psi_{s(\text { root })}\right)$ potentials were determined using a vapor pressure osmometer (VAPRO 5600 , ELITech, Puteaux, France) and calculated using the Van't Hoff equation, expressed as MPa. Leaf temperature was measured using a digital infrared thermometer (Model TI-920, Instrutherm Ltda, São Paulo, SP, Brazil), approximately $15 \mathrm{~cm}$ from the leaf limb. The measurements were performed at 09:00 $\mathrm{h}$, with the chamber at $25^{\circ} \mathrm{C}$.

Gas exchange and chlorophyll a fluorescence analysis. Gas exchange was measured in fully expanded leaves to determine the photosynthetic rate $\left(A, \mu \mathrm{mol} \mathrm{CO}_{2} \mathrm{~m}^{-2} \mathrm{~s}^{-1}\right)$, stomatal conductance $\left(g_{\mathrm{s}^{\prime}}, \mathrm{mol} \mathrm{H}_{2} \mathrm{O}\right.$ $\left.\mathrm{m}^{-2} \mathrm{~s}^{-1}\right)$, transpiration rate $\left(E, \mathrm{mmol} \mathrm{H}_{2} \mathrm{O} \mathrm{m}^{-2} \mathrm{~s}^{-1}\right)$, and the ratio of internal and external $\mathrm{CO}_{2}$ concentration $\left(C_{i} / C_{a}\right)$. We further estimate intrinsic water-use efficiency $\left(A / g_{\mathrm{s}}\right)$ and instantaneous carboxylation efficiency $\left(A / C_{\mathrm{i}}\right)$. The measurements were performed using an infrared gas analyzer (IRGA, LI-6400xrt, Licor $\circledast$, Nebraska, USA), under constant photosynthetically active radiation (PAR, $1000 \mu \mathrm{mol}$ $\left.\mathrm{m}^{-2} \mathrm{~s}^{-1}\right)$ at the environmental $\mathrm{CO}_{2}$ concentration $\left(\sim 430 \mu \mathrm{mol} \mathrm{mol}{ }^{-1}\right)$, temperature $\left(\sim 25^{\circ} \mathrm{C}\right)$, and relative humidity ( 65\%). Chlorophyll a fluorescence was measured using the IRGA coupled to a leaf chamber fluorometer (6400xt, Licor®, Nebraska, USA). The minimal chlorophyll fluorescence $\left(F_{0}\right)$ and maximum quantum yield of photosystem II (PSII) (Fv/Fm) was measured after 30 minutes of dark adaptation. In light-adapted leaves, the apparent electron transport rate (ETR), the fraction of opened PSIl reaction centers $(\mathrm{qL})$, the effective quantum yield of $P S I I\left(Y_{\|}\right)$, and the yield of non-photochemical quenching $\left(\mathrm{Y}_{\mathrm{NPQ}}\right)$ were obtained.

Determination of antioxidant enzyme activities. To determine the activities of superoxide dismutase (SOD), catalase (CAT), ascorbate peroxidase (APX), and total peroxidase (POX), fresh leaf tissue was homogenized in potassium phosphate buffer solution ( $\mathrm{pH} 6.8$ ). SOD activity was determined by measuring the ability to photochemically reduce $p$-nitrotetrazolium blue (NBT), at $560 \mathrm{~nm}$ in a spectrophotometer (Evolution 60S, Thermo Fisher Scientific Inc., MA, USA), according to (Del Longo et al., 1993), considering that one SOD unit was defined as the amount of enzyme required to inhibit NBT photoreduction by $50 \%$. CAT activity was assayed according to the method described byHavir and McHale ${ }^{88}$ and calculated as the rate of hydrogen peroxide $\left(\mathrm{H}_{2} \mathrm{O}_{2}\right)$ decomposition at $240 \mathrm{~nm}$ for $3 \mathrm{~min}$ at $25^{\circ} \mathrm{C}$, using a molar extinction coefficient of $36 \mathrm{M}^{-1} \mathrm{~cm}^{-1}$. APX activity was determined according toNakano and Asada ${ }^{89}$ and was measured as the rate of ascorbate oxidation at $290 \mathrm{~nm}$ within 1 min at $25^{\circ} \mathrm{C}$, using a molar extinction coefficient of $0.0028 \mathrm{M}^{-1} \mathrm{~cm}^{-1}$. POX activity was measured following the method described by Kar and Mishra ${ }^{90}$. Purpurogallin production was determined by increasing the absorbance of reaction at $420 \mathrm{~nm}$ for $1 \mathrm{~min}$ at $25^{\circ} \mathrm{C}$, using the extinction coefficient of $2.47 \mathrm{mM}^{-1} \mathrm{~cm}^{-1}$ 91 . Enzyme activity was expressed based on protein, the concentration of which was determined according to the Bradford method.

Leaf morphoanatomical characterization. Samples $\left(\sim 3 \mathrm{~cm}^{2}\right)$ from the middle region of the last fully expanded leaf were collected and fixed in Karnovsky solution. After $24 \mathrm{~h}$, the material was pre-washed in phosphate buffer and dehydrated in a gradual ethyl alcohol series, pre-infiltered and infiltered in 
historesin (Leica, Germany), according to the manufacturer's recommendation. Samples were then transversely sectioned to 5 - $\mu \mathrm{m}$ thickness in a rotating microtome (1508R model, Logen Scientific, China). Sections were stained with toluidine blue $(0.05 \%$ in $0.1 \mathrm{M}$ phosphate buffer, $\mathrm{pH} 6.8)$ and anatomical observations of adaxial and abaxial epidermis, palisade and spongy parenchyma and mesophyll were made using images photographed with an Olympus microscope (BX61, Olympus, Tokyo, Japan) coupled to a DP-72 camera using the light-field option. The micromorphometry measurements were obtained from the previous images using ImageJ software (Image Processing and Analysis in Java, v.147, USA). Ten observations per replicate were measured for each structure evaluated.

Growth analysis. Growth parameters such as plant height $(\mathrm{PH}, \mathrm{cm})$, stem diameter (SD, $\mathrm{mm})$, and leaf area (LA) were determined. Shoot (leaves and stem) and roots were separated and dried at $65^{\circ} \mathrm{C}$ for $72 \mathrm{~h}$ to obtain the shoot dry matter (SDM, g) and root dry matter (RDM, g). The ration RDM/SDM were also calculated.

Metabolic extraction and analysis. Leaf samples were collected and immediately immersed in liquid nitrogen, and later homogenized and lyophilized. For metabolites extraction, the samples were microwave dried to prevent metabolic turnover ${ }^{92}$ and then approximately $40 \mathrm{mg}$ of dry leaf samples was extracted in methanol/chloroform/water $(12: 5: 3, \mathrm{v} / \mathrm{v} / \mathrm{v})$ at $75^{\circ} \mathrm{C}$ for $30 \mathrm{~min}$. The water fraction of the extraction mixture consisted of a $0.1 \%$ solution of internal standard. Samples were centrifuged and the supernatants were collected and mixed to chloroform and Milli-Q water to facilitate phase separation. The water-methanol soluble fractions were collected and stored at $-20^{\circ} \mathrm{C}$ for further analysis.

Analysis of soluble carbohydrates, sugars and organic acids were performed using gas chromatography (Agilent 7890A) coupled to triple quadrupole mass spectrometer (7000 Agilent Technologies Inc, Santa Clara, CA, USA). A HP5 column (0.25-mm internal diameter, 30-m long, 0.25- $\mu \mathrm{m}$ film thickness) was used for chromatographic separation. Extracts were dried down in a SpeedVac and resuspended in 400ul of anhydrous pyridine. Samples were then derivatised using a 1:10 mixture of N,OBis(trimethylsilyl)trifluoroacetamide (BSTFA): trimethylcholorsilane (TMCS). Samples were incubated for $35 \mathrm{~min}$ at $75^{\circ} \mathrm{C}$ and were analysed using GC-MS within $24 \mathrm{~h}$. A 20:1 split injection was made at $300^{\circ} \mathrm{C}$ initial oven temperature program of $60^{\circ} \mathrm{C}$ for $2 \mathrm{~min}$, ramping to $220^{\circ} \mathrm{C}$ at $10^{\circ} \mathrm{C} \mathrm{min}{ }^{-1}$ (hold for $5 \mathrm{~min}$ ) then ramping at $10^{\circ} \mathrm{C} \mathrm{min}-1$ to $300^{\circ} \mathrm{C}$ (hold for $5 \mathrm{~min}$ ). Peak integration was made using Agilent MassHunter software (Agilent). A mixed standard was made from a stock solution containing $500 \mu \mathrm{g}$ $\mathrm{mL}^{-1}$ of each analyte. Appropriate aliquots were taken to make standard concentrations between 0.5 and $50 \mu \mathrm{g} \mathrm{mL}^{-1}$. The results were expressed based on dry weight.

Analysis of amino acids was performed using the underivatized extracts on a 1290 Infinity liquid chromatography (LC)-MS system (6520 QTOF, Agilent Technologies Inc, Santa Clara, CA, USA). A 3.5 $\mu \mathrm{L}$ sample was injected into a Zorbax SB-C18 column $(2.1 \times 150 \mathrm{~mm}, 3.5 \mu \mathrm{m})$ and separation was achieved by gradient elution with water and methanol. The QTOF was tuned to operate at low-mass range $(<1700$ $A M U)$. Data acquisition was performed in scan mode $(60-1700 \mathrm{~m} / \mathrm{z})$ and ionization performed in positive ion mode. LC-MS results were identified based on their retention times relative to standards as 
well as their formula mass. Peaks were integrated and their relative quantities were calculated using MassHunter software (Agilent ${ }^{\circledR}$ ). A mixed standard was made from a stock solution containing $500 \mu \mathrm{g}$ $\mathrm{mL}^{-1}$ of each analyte. The solutions were kept frozen at $-20^{\circ} \mathrm{C}$. Appropriate aliquots are taken to make resulting standard concentrations between 0.1 to $20 \mu \mathrm{g} \mathrm{mL}^{-1}$. The results were expressed based on dry weight.

Metabolic network analysis. Metabolomics and physiological parameters data were used to create correlation-based networks, in which the nodes are the metabolites and the links are the strength of debiased sparse partial correlation (DSPC) coefficient $(r)^{93}$. The correlation-based networks were created by using Metscape on CYTOSCAPE ${ }^{94,95}$ and limiting the significance of correlation between nodes to $P<$ 0.05 or by restricting $r$ values to $-0.5<r>0.5^{96}$. The parameters network density, network heterogeneity and network centralization were obtained using the java plugin NetworkAnalyzer on CYTOSCAPE software ${ }^{97}$.

Statistical analysis. The data were subjected to factorial analysis of variance and the means were compared using the Tukey test $(p<0.05)$, using Analysis System Program Variance (SISVAR, version 5.4). The metabolomics data were analysed by multivariate analysis such as partial least square-discriminant analysis (PLS-DA) and biomarker analysis based on receiver operating characteristic (ROC) curves using the MetaboAnalyst platform ${ }^{98}$. These metabolic analyses were normalized by using Log and Autoscaling transformations on MetaboAnalyst.

\section{Results}

The combination of water deficit and high temperature exacerbate stress-induced physiological changes. Increases in leaf temperature were recorded under all stress treatments, with increments up to $3.71^{\circ} \mathrm{C}$ in WD+HT-treated plants compared to WW plants (Figure 1A). Lower values of $\Psi_{\mathrm{w}(\mathrm{am})}, \Psi_{\mathrm{s}(\text { leaf })}$ and $\Psi_{\mathrm{s}(\text { root })}$ was observed in plants under WD+HT compared to the WW condition, with no major difference among the cultivars under this condition (Figure 1B-D). WD and WD+HT reduced $A, g_{\mathrm{s}}$ and $E$ in all soybean cultivars when compared to their respective controls, but this was not reflected in $C_{\mathrm{i}} / C_{\mathrm{a}}$ ratio (Figure $2 \mathrm{~A}$ D). The 7011 and 7209 cultivars showed the lowest values of $A, g_{\mathrm{s}}$ and $E$ under WD+HT when compared to the others cultivars and treatments. (Figure $2 A-C$ ). The intrinsic water-use efficiency (iWUE - $A / g_{s}$ ) increased in WD and WD+HT treatments, but no major differences among the cultivars was observed (Figure 2E). The $A / C_{\mathrm{i}}$ ratio decreased mainly in 7011 and 7209 cultivars under WD+HT (Figure 2F). The impact of the stress on gas exchange parameters did not resemble those related to leaf temperature and hydric status. It appears that the reductions in gas exchange parameters observed under WD+HT are most associated to WD rather than the HT effect.

The minimum fluorescence $\left(F_{0}\right)$ and the maximum quantum yield of $P S I I\left(F_{v} / F_{m}\right)$ presented higher and lower values in response to $\mathrm{WD}+\mathrm{HT}$, compared to other treatments (Figures $3 \mathrm{~A}-\mathrm{B}$ ). The effective quantum yield of PSII $\left(Y_{\|}\right)$, coefficient quenching $(\mathrm{qL})$, electron transport rate (ETR) and the yield of non- 
photochemical quenching $\left(\mathrm{Y}_{\mathrm{NPQ}}\right)$ showed significant interaction between cultivation conditions and cultivars (Figure 3). $Y_{\|}$and ETR values were reduced due to combined stress for cultivars 7011 and 7209 (Figure 3C, 3E). $\mathrm{Y}_{\mathrm{NPQ}}$ increased for Desafio, 7011 and 7739 cultivars in response to $\mathrm{HT}$ treatment (Figure 3F). Under $W D+A T$, all cultivars increased $\mathrm{Y}_{\mathrm{NPQ}}$, but more pronounced for 7209 and 7011 (Figure 3F).

Antioxidant enzyme activity under stress conditions. SOD activity was higher in cultivar 7011 under WD, cultivar 7739 under HT, and cultivar 7209 exposed to WD+HT (Figure 4A). Under WD, the Desafio, 7209 and 7739 cultivars presented higher APX activities, while in the WD+HT treatment the Desafio and 7739 cultivars had higher values of APX activity (Figure 4B). Lower APX activity was observed in the cultivar 7011 under WD and WD+HT conditions. POX activity increased in all treatments, especially in WD+HT (Figure 4C). Greater CAT activities were observed in plants exposed to WD, followed by WD+HT treatment (Figure 4D). In summary, the activity of antioxidant enzymes differs among the stress conditions, in which CAT and APX activities increased mainly under WD and WD+HT, respectively.

Impact of water deficit combined with high temperature on leaf anatomy and plant growth. HT increased the thickness of both palisade and spongy parenchymas in Desafio and 7011 cultivars, which leads to an increase in mesophyll cells and leaf thickness, mainly in 7011 (Supplementary Figure S1 online). WD+HT treatment reduced mesophyll, and palisade and spongy parenchymas thickness in the cultivar 7011 (Supplementary Figure S1A-C online), and resulted in smaller leaf thickness compared to the other cultivars (Supplementary Figure S1D online). Higher adaxial and abaxial epidermis thickness were observed for the cultivar 7011 and lower values for 7209 , both exposed to WD treatment (Supplementary Figure S1E-F online).

Plant height $(\mathrm{PH})$ showed lower values when exposed to WD and WD+HT (Supplementary Figure S2A online), being more pronounced in Desafio and 7739 cultivars. HT treatment promoted an increase in stem diameter (SD, Supplementary Figure S2B online) in 7011 and 7739 . Cultivars 7011 and 7739 presented larger leaf areas (LA) when subjected to HT (Supplementary Figure S2C online), while LA was reduced in cultivar 7011 exposed to WD. Shoot dry matter (SDM) was increased in cultivars 7011 and 7739 in HT condition, and reduced in cultivar 7011 under WD+HT (Supplementary Figure S2D online). Reductions in root dry mass (RDM) were observed in all treatments (Supplementary Figure S2E online), while for RDM/SDM was reduced only in HT- and WD+HT-treated plants (Supplementary Figure S2F online).

\section{Soybean metabolic responses to water deficit, high temperature and the combination of both stresses.}

Thirty metabolites pertaining to the classes of sugars, amino acids, organic acids and others were identified in all treatments (Figure 5A) and used for multivariate and correlation-based network analyses. The partial least square discriminant analysis (PLS-DA) combining the data of each treatment from all cultivars revealed that WD and $H T$ treatments were slightly separated from WW, whilst WD+HT is clearly the most different treatment at metabolic level. This is evidenced by the separation of WD+HT from the other treatments by the first component, that represents $45.8 \%$ of the variability of the model (Figure $5 \mathrm{~B}$ ). Fifteen metabolites were found with VIP score higher than 1 , meaning that they greatly contribute to the 
discrimination found in the PLS-DA model. Most of them are amino acids and have higher accumulation in WD+HT compared to WW, WD and HT treatments (Figure 5C). Surprisingly, very few significant correlations were observed among the metabolites in each treatment, leading to correlation-based networks that were poorly connected (Supplementary Figure S4 online). However, WD and WD+HT have metabolic networks with higher density, as compared to WW (Supplementary Table S1 online). Additionally, increased network heterogeneity and decreased network centralization was observed in all stress treatments compared to WW (Supplementary Table S1 online).

We next investigated which metabolites are biomarkers of each stress condition. A total of 21, 23, and 27 metabolites were identified as biomarkers of WD, HT and WD+HT stress conditions, respectively (Figure 6; Supplementary Figures S5-S6 online). Among them, only ribose was identified as biomarker with decreased content in all stress conditions (Supplementary Figure S7 online), whilst several amino acids plus pinitol and D-chiro-inositol were identified as biomarkers and with increased content in all stress conditions (Supplementary Figure S7 online). Interestingly, myo-inositol was found as WD and WD+HT biomarker, but with increased and decreased content in WD and WD+HT, respectively, compared to WW conditions (Supplementary Figure S7 online). Similarly, GABA (gamma-aminobutyric acid) was simultaneously found as biomarker of both HT and WD, but with increased and decreased content under HT and WD, respectively (Supplementary Figure S7 online). Sucrose and proline, two important osmoprotective compounds, were found as biomarkers with increased content under both HT and $\mathrm{WD}+\mathrm{HT}$, compared to WW condition (Supplementary Figure S7 online).

Cultivar-specific stress metabolic responses. We next analysed the effect of the stress treatments in each cultivar at metabolic level. The PLS-DA results resemble the general ones described above, in which $\mathrm{WD}+\mathrm{HT}$ treatment is clearly separated from the other treatments in each cultivar (Figures 6A-D). Regarding the VIP scores of this analysis, 15, 16, 16 and 14 metabolites have VIP scores higher than 1 in 7011, 7209, 7739 and Desafio cultivars, respectively (Figure 6E-H). Ten of these metabolites are common among all cultivars, including seven amino acids (His, Leu, lle, Val, Trp, Asn and GIn) plus pinitol, sucrose and glucose (Supplementary Figure S8 online).

Integrating metabolomics with physiological parameters. We next integrated all data and compared the treatments by multivariate and correlation-based network analyses. PLS-DA analysis using all data revealed the same pattern previously observed using the metabolic data, in which WD+HT is separated from all other conditions by the first component, whilst HT was separated from WW and WD by the second component (Figure 7). Network analysis revealed that the nodes are displaced into several subnetworks in all conditions. The subnetworks are mostly composed by nodes of the same scale of observation. For instance, nodes related to photochemical reactions (e.g. $F_{v} / F_{m}, q_{L}$ and $F_{0}$ ) are connected to each other but not to any other parameter of the network. This is also observed for growth and gas exchange parameters, especially under WW conditions (Figure 8A). However, certain metabolites are connected to important physiological parameters. For example, malate is negatively correlated to leaf temperature and Tyr and GIn are positively correlated with number of nodes and leaf area, respectively, under WW condition (Figure 8A). By contrast, Gln is connected in a subnetwork that contains root $\Psi_{S}$ and 
the DW ratios of root/shoots and shoots/roots under WD (Figure 8B). Furthermore, whilst $A / E$ was solely connected to $E$ under WW and $\mathrm{HT}$ conditions (Figure $8 \mathrm{~A}, \mathrm{C}$ ), $A / E$ was positively correlated to $\Psi \mathrm{p}$ under WD condition (Figure 8B).

Under WD+HT condition, $A / E$ is part of a subnetwork composed by iWUE, $C_{\mathrm{i}}, C_{\mathrm{i}} / C_{\mathrm{a}}, \mathrm{APX}$ and the metabolites sucrose, fructose and histidine (Figure 8D). Interestingly, $A$ was not correlated to any parameter under WW condition, but it was negatively correlated to $\mathrm{Y}_{\mathrm{NPQ}}$ under WD and $\mathrm{HT}$ conditions and strongly and positively correlated to $g_{\mathrm{s}}$ under WD+HT condition (Figure 8A-D). Lys was found to be a hub connecting physiological $\left(\Psi_{\mathrm{w}(\mathrm{am})}\right)$, root $\Psi_{\mathrm{s}}$, leaf $\Psi_{\mathrm{s}}$, plant height and number of nodes) with maltose and amino acids (Val, Leu, Tyr and Thr) under WD+HT condition (Figure 8D). The analysis of the network parameters revealed slight decreases and increases in network density and centralization under stress conditions, whilst the increase in network heterogeneity was more prominent under all stress treatments (Supplementary Table S1 online).

\section{Discussion}

Identifying the mechanisms that contribute to the acclimation of soybean plants under abiotic stress conditions is pivotal for the selection of tolerant cultivars and to pave the way to obtain new tolerant cultivars through genetic engineering of plant metabolism ${ }^{36}$. Here, soybean cultivars showed differential responses to WD, HT and the combination of both stress conditions. Lower water potential has been described as a WD tolerance strategy, given that it entails the activation of osmotically compatible solute synthesis ${ }^{37}$, as observed here by the increases in sucrose, proline and sugar alcohols in soybean plants under WD and WD+HT. Osmotic adjustment induces increased turgidity of plant cells, maintaining or at least minimizing the reduction in both plant growth and transpiration ${ }^{38}$, which, in turn, facilitate soil water uptake and leaf cooling, crucial for plants under WD and HT conditions. However, stomata, the master regulator of transpiration and photosynthesis, respond to a wide range of stimulus, not only plant water status ${ }^{39,40}$. Thus, despite negatively affecting photosynthetic performance ${ }^{41}$, reduced $g_{s}$, which is closely associated to lower water potential, can represent a stress-avoidance mechanism ${ }^{42}$. Here, stomatal closure limited the transpiration rate of soybean plants, leading to an increase of $3.7^{\circ} \mathrm{C}$ in average in leaf temperature under WD+HT conditions. The heat stress per se did not affect the photosynthetic rate of soybean cultivars, suggesting that drought is a major stress factor for photosynthetic efficiency under WD+HT conditions. This idea is supported by the maintenance of $A, g_{\mathrm{s}}, E$, $A / \mathrm{Ci}$, and $\mathrm{Y}_{\|}$values under $\mathrm{HT}$ conditions. Maintaining leaf temperature is further important to avoid protein denaturation and loss of membrane integrity ${ }^{43}$. However, plants need to balance the maintenance of photosynthesis with lower water loss through transpiration toward iWUE improvement, which was indeed observed here in soybean plants exposed to WD and WD+HT conditions.

Soybean plants under WD+HT had increased minimum fluorescence $\left(\mathrm{F}_{0}\right)$ of dark-adapted leaves and reduced $Y_{\|}$values, indicating damage to the antenna complex of the PSII ${ }^{44}$. To avoid excess energyassociated oxidative stress, plants generally activate protective mechanisms such as carotenoid 
accumulation ${ }^{45}$ and increased NPQ-mediated dissipation ${ }^{46}$. Nevertheless, these mechanisms were not effective in avoiding the reductions observed in $Y_{\|}$and ETR, mainly in cultivars 7011 and 7209 , in response to $\mathrm{WD}+\mathrm{HT}$. By contrast, no substantial differences were found in photochemical-related parameters in plants under HT conditions. High temperatures are related to an increase membrane fluidity, promoting changes in the assembling of membrane-inserted proteins ${ }^{47}$. Maintaining membrane stability is an important factor in stress tolerance. Indeed, thermal stress tolerance of Arabidopsis plants has been attributed by their ability to maintain chloroplast membrane integrity 48 .

To avoid stress-induced oxidative imbalances, plants generally increase both the activity of antioxidant enzymes and the thermal dissipation of excess light absorbed via $\mathrm{Y}_{\mathrm{NPQ}}$. The activation of $\mathrm{Y}_{\mathrm{NPQ}}$ is competitive with photochemical processes, meaning that increased $\mathrm{Y}_{\mathrm{NPQ}}$ may be followed by reductions in photochemical efficiency ${ }^{49}$. For instance, the increase in $\mathrm{Y}_{\mathrm{NPQ}}$ in corn plants exposed to WD was accompanied by decreases in photosynthesis and plant growth ${ }^{50}$. Here, the increase in $\mathrm{Y}_{\mathrm{NPQ}}$ was mainly observed in the genotypes 7011 and 7209 under WD+HT. Interestingly, these genotypes have the lowest $A$ and APX activity under WD+HT. This suggests that they are the most WD+HT-sensitive cultivars, as compared to Desafio and 7739. However, no substantial differences in plant growth and plant anatomy parameters were observed between the genotypes. These results indicate that the stress responses observed in 7011 and 7209 cultivars were sufficient to avoid deleterious effects on growth during the period analysed here. However, higher $A$ and APX activity may confer great advantage for Desafio and 7739 cultivars in longer periods of WD+HT, suggesting that total APX activity is a potential marker for breeding programs to obtain plants more tolerant to combined stresses. However, given that APX family is composed by several isoforms that are located in different subcellular localizations and play different roles under stress conditions ${ }^{51-53}$, further studies aiming to unveil the contribution of soybean APX isoforms to $\mathrm{WD}+\mathrm{HT}$ tolerance are now required to fully comprehend the role of APXs in plant acclimation/tolerance to WD+HT.

Abiotic stresses induce a wide range of metabolic changes in plants, which vary according to the species and the level of stress ${ }^{12,54,55}$. The availability of free amino acids generally increases stress tolerance in plants due to their participation in physiological mechanisms such as osmotic adjustment, ROS detoxification, intracellular $\mathrm{pH}$ regulation and by sustaining alternative mitochondrial respiratory pathways ${ }^{56-59}$. Here, PLS-DA and biomarker analyses revealed that several amino acids are implicated in the soybean responses to WD and $\mathrm{HT}$, in which several of them have increased content in all stress conditions. Among these amino acids, arginine has structural importance for proteins, participates in nitrogen re-distribution and is a precursor to the synthesis of polyamines and proline ${ }^{60}$. Proline was found in the VIP score list of PLS-DA, with a more prominent accumulation under WD+HT followed by WD condition. Proline accumulation contributes to maintaining the $\mathrm{NADP}^{+} / \mathrm{NADPH}$ ratio at levels adequate for cell metabolism ${ }^{61}$ and has been shown to be an important osmoregulatory mechanism for soybean acclimation to WD periods ${ }^{62}$. Indeed, proline was directly linked to root osmotic potential in the WD network, highlighting its role as osmo-protectant. 
Glycine is also known to be accumulated in response to WD in plants ${ }^{29}$. The level of glycine has been shown to increase in Solanum lycopersicum exposed to combined heat and salinity stress, acting as osmo-protectant ${ }^{63}$. Similarly, increases in levels of aromatic amino acid (tyrosine and tryptophan), as observed here in soybean plants, were also reported in wheat ${ }^{64}$, soybean ${ }^{29}$ and chickpea ${ }^{65}$ under drought conditions. These amino acids may act as alternative sources of metabolic energy ${ }^{65}$, and play important roles in ion transport, maintenance of water balance and elimination of ROS ${ }^{64}$. The antioxidant effect of aromatic amino acids such as histidine prevent the intensification of damage from stress, as observed in drought-tolerant chickpeas ${ }^{65}$. The increase in isoleucine and leucine branched chain amino acid levels in soybean plants may be a mechanism to provide carbon skeletons for respiration during stress, as was observed in several other species under different stress conditions, including WD $57,59,66$. In addition, increased asparagine content was observed here, which is important for maintaining osmotic pressure and translocating nitrogen 67 .

Our results also highlight that glutamine accumulation is important to plants under WD+HT. This amino acid was found in the PLS-DA VIP score list of all genotypes and identified as a WD+HT biomarker. Glutamine, in addition to its role in nitrogen metabolism, is an efficient signaling molecule related to metabolic regulation, stimulating defense responses in plants under stress conditions ${ }^{68}$. For instance, increased glutamine levels rapidly induced the expression of genes involved in the regulation of stress defense responses in rice plants ${ }^{69}$. Furthermore, glutamine metabolism is closely associated to the production of nitric oxide, proline and GABA, that have been described as important components of plant stress responses ${ }^{15,70}$. Taken together, our results highlight the important role of amino acid metabolism for plant stress responses.

Beyond the changes in amino acids, the metabolism of sugars and polyols was altered under stress. Sugars and polyols are important for energy supply and acting as osmoprotectors in plants ${ }^{64,71}$. Here, we observed that soybean cultivars under WD+HT resulted in increased levels mainly of sucrose and pinitol. Sucrose is the main product used in carbon distribution for non-photosynthetic tissues ${ }^{72}$, and, as polyols (pinitol and myo-inositol), act in the process of osmotic adjustment and the prevention of oxidative damage ${ }^{58,73,74}$. It's important to note that we also observed an increase in myo-inositol in WD treatment but a decrease under WD+HT in soybean plants. The methylation of pinitol is linked to the $S$ adenosylmethionine (SAM) cycle ${ }^{17}$; thus, the synthesis of pinitol is linked to HT via photorespiration and would exhibit a demand for myo-inositol to be converted to pinitol in soybean plants. Furthermore, decrease maltose content was identified as WD+HT biomarker and was connected to a subnetwork composed by amino acids and both root and leaf osmotic potentials. This suggests that the metabolism of maltose, which is closely associated to hexose and starch, is also important for soybean stress acclimation. This idea is supported by the fact that starch degradation is an important mechanism to provide substrates for the synthesis of osmo-protectants such as sugars, polyols and proline under WD 75,76 . Therefore, decreased maltose content may be associated with a redirection of carbon flux from starch synthesis to starch degradation. In turn, starch-derived carbons could be used to sustain the 
synthesis of sugars, polyols and amino acids in a source-limited conditions, i.e., in a period in which the photosynthetic rate is reduced, as observed in WD+HT conditions.

Stress responses involve changes at different levels, from epigenetic and gene expression to ultimately physiological and anatomical changes. Thus, in order to fully understand plant stress responses, is necessary to adopt non-reductionist approaches ${ }^{77,78}$. Systems biology analysis have the great advantage to overcome the barrier imposed by the reductionism perspective that simplify complex mechanisms such as plant stress responses ${ }^{79,80}$. This is especially important considering that complex biological systems are defined by non-linear relationships and cannot be interpreted by the sum of their components ${ }^{81,82}$. Furthermore, emergent properties, which raise from the interaction among the components of the system, are not visualized by reductionism approaches ${ }^{83}$. Taking this into account, we have integrated metabolic, photosynthetic and morpho-anatomical data by multivariate and correlation-based network analyses ${ }^{84}$. Interestingly, PLS-DA clearly separated the plants under WD+HT from plants under WW, WD and HT. This strongly suggests that the combination of both stress factors is an emergent property of the system, in which the metabolic responses to the combination of WD+HT cannot be interpreted by solely summing the responses observed in these stresses separately.

The metabolic network analysis further corroborates this idea, given that the density, centralization and heterogeneity of the metabolic network under WD+HT did not resemble the values observed under these stresses separately. Interestingly, substantial increases in network heterogeneity were observed in both metabolic and global networks under all stress conditions, when compared to WW plants. Additionally, plants under stress have a higher connection among components of different biological levels. For instance, whilst the subnetworks were mostly composed by nodes of the same level of organization (i.e. morphological, physiological and metabolic) under WW conditions, the imposition of stress increased the connectivity of nodes from different levels. This is evidenced by the connections observed between different amino acids such as Ser, Asp, Leu, Glu, Gln, Arg and Lys that belongs to sub-networks composed by physiological and biochemical parameters under stress. Taken together, these results highlight that the stress conditions used here substantially alter the topology of both metabolic and the global network, in which the appearance of hub-like nodes, measured here through network heterogeneity, seem to be a response to stress. Higher network heterogeneity highlights the predominance of hubs in the network, i.e. the presence of nodes with high degree of connection ${ }^{85}$. Hubs are important not only to change network topology but also to integrate different levels of the system, probably conferring a higher degree of stability to the system ${ }^{83}$.

\section{Conclusions}

Water deficit negatively affected the metabolism of soybean plants, with an exacerbated effect when combined with high temperature. Metabolomics analysis highlight that the metabolic responses of plants under WD+HT differ substantially from both stresses isolated, which has several implications for molecular breeding toward WD+HT stress tolerance improvement in the current climate change scenario. 
Our results suggest that osmotic adjustment mainly from proline and pinitol accumulation associated with increased APX activity were important factors in the acclimation of soybean plants. We further demonstrate that increased amino acid content and decreased content of both maltose and myo-inositol were found as WD+HT biomarkers, highlighting the importance of amino acids and carbohydrate metabolisms for soybean stress acclimation. The discussion must not contain subheadings.

\section{Declarations}

\section{Conflict of Interest}

The authors declare that they have no conflict of interest.

\section{Data availability}

All data generated or analysed during this study are included in this published article (and its Supplementary Information files).

\section{Research involving plants statement}

This study was developed with commercial seeds, therefore non-exotic or at risk of extinction, under controlled conditions, meeting all institutional, national and international guidelines and legislation for cultivated plants.

\section{Acknowledgements}

This work was supported by the National Council for Scientific and Technological Development (CNPq, grant nos. 551456/2010-8 and 552689/2011-4), the Goiano Federal Institute of Education, Science and Technology (IFGoiano-RV, grants no. DPPG 045/2014), Rio Verde campus, and the Foundation for Research Support of the State of Goiás (FAPEG, grant no. DCR 14/2013). C.M., P.F.B. and A.A.S. are grateful to Coordination for the Improvement of Higher Education Personnel (CAPES), and F.B.F.S. and A.A.R. to CNPq, for fellowships. D.M.D. (301178/2017-8) and A.C.C. (312917/2017-1) also thank CNPq for productivity fellowship. A.M. acknowledges the Australian Research Council Future Fellowship Scheme (FT120100200).

\section{Author contributions}

R.G.V., C.M., and A.C.C. design the research. R.G.V., C.M., F.B., and L.M.F.M. conducted the experiments and performed physiological measurements. P.F.B., D.F., and A.M. performed metabolites analysis. A.A.R. performed anatomical analysis. F.B.S.F. performed the multivariate analysis. R.G.V., C.M., F.B.S., D.M.D., A.A.S., A.M., and A.C.C. analysed the data. R.G.V., C.M., F.B.S., A.A.S., and D.M.D. wrote the manuscript with contributions from A.M. and A.C.C. All authors read and approved the final version of the manuscript. 


\section{References}

1. Schauberger, B., Rolinski, S., Schaphoff, S. \& Müller, C. Global historical soybean and wheat yield loss estimates from ozone pollution considering water and temperature as modifying effects. Agricultural and Forest Meteorology 265, 1-15 (2019).

2. Peña-Gallardo, M. et al. Article (refereed) - postprint. Agricultural and Forest Meteorology $264,40-55$ (2019).

3. Djanaguiraman, M., Schapaugh, W., Fritschi, F., Nguyen, H. \& Prasad, P. V. V. Reproductive success of soybean (Glycine max L. Merril) cultivars and exotic lines under high daytime temperature. Plant Cell and Environment 42, 321-336 (2019).

4. CONAB. Acompanhamento da Safra brasileira. Grãos - Safra 2018/19. Companhia Nacional de Abastecimento: Brasília (2019).

5. INMPE. Dados históricos. Instituto Nacional de Meteorologia, https://portal.inmet.gov.br/dadoshistoricos. (2020).

6. Gago, J. et al. Integrative field scale phenotyping for investigating metabolic components of water stress within a vineyard. Plant Methods 13, 1-14 (2017).

7. Kuromori, T., Seo, M. \& Shinozaki, K. ABA Transport and plant water stress responses. Trends in Plant Science 23, 513-522 (2018).

8. Hatzig, S. et al. Early osmotic adjustment responses in drought-resistant and drought-sensitive oilseed rape. Journal of Integrative Plant Biology 56, 797-809 (2014).

9. Harsh, A. et al. Effect of short-term heat stress on total sugars, proline and some antioxidant enzymes in moth bean (Vigna aconitifolia). Annals of Agricultural Sciences 61, 57-64 (2016).

10. Dumschott, K., Richter, A., loescher, W. \& Merchant, A. Post photosynthetic carbon partitioning to sugar alcohols and consequences for plant growth. Phytochemistry 144, 243-252 (2017).

11. Dumschott, K., Dechorgnat, J. \& Merchant, A. Water deficit elicits a transcriptional response of genes governing d-pinitol biosynthesis in soybean (G/ycine max). International Journal of Molecular Sciences 20, 1-11 (2019).

12. Fàbregas, N. \& Fernie, A. R. The metabolic response to drought. Journal of Experimental Botany 70, 1077-1085 (2019).

13. Cardoso, A. A., Randall, J. M. \& McAdam, S. A. M. Hydraulics regulate stomatal responses to changes in leaf water status in the fern Athyrium filix-femina 1. Plant Physiology 179, 533-543 (2019).

14. Da Fonseca-Pereira, P., Daloso, D. M., Gago, J., Nunes-Nesi, A. \& Araújo, W. L. On the role of the plant mitochondrial thioredoxin system during abiotic stress. Plant Signaling and Behavior 14, 1-5 (2019).

15. de Sousa, L. F. et al. Improving water use efficiency by changing hydraulic and stomatal characteristics in soybean exposed to drought: the involvement of nitric oxide. Physiologia Plantarum 168, 576-589 (2020).

16. Rizhsky, L. et al. When defense pathways collide. The response of arabidopsis to a combination of drought and heat stress. Plant Physiology 134, 1683-1696 (2004). 
17. Hare, P. D., Cress, W. A. \& Van Staden, J. Dissecting the roles of osmolyte accumulation during stress. Plant, Cell and Environment 21, 535-553 (1998).

18. Obata, T. et al. Metabolite profiles of maize leaves in drought, heat, and combined stress field trials reveal the relationship between metabolism and grain yield. Plant Physiology 169, 2665-2683 (2015).

19. Siddiqui, M. H. et al. Response of different genotypes of faba bean plant to drought stress. International Journal of Molecular Sciences 16, 10214-10227 (2015).

20. Sicher, R. C. Temperature shift experiments suggest that metabolic impairment and enhanced rates of photorespiration decrease organic acid levels in soybean leaflets exposed to supra-optimal growth temperatures. Metabolites 5, 443-454 (2015).

21. Niu, Y. \& Xiang, Y. An overview of biomembrane functions in plant responses to high-temperature stress. Frontiers in Plant Science 9, 1-18 (2018).

22. Hasanuzzaman, M., Nahar, K., Alam, M. M., Roychowdhury, R. \& Fujita, M. Physiological, biochemical, and molecular mechanisms of heat stress tolerance in plants. International Journal of Molecular Sciences 14, 9643-9684 (2013).

23. Chen, K. et al. Ascorbic acid alleviates damage from heat stress in the photosystem II of tall fescue in both the photochemical and thermal phases. Frontiers in Plant Science 8, 1-9 (2017).

24. Tohge, T., De Souza, L. P. \& Fernie, A. R. Current understanding of the pathways of flavonoid biosynthesis in model and crop plants. Journal of Experimental Botany 68, 4013-4028 (2017).

25. Nahar, K., Hasanuzzaman, M., Alam, M. M. \& Fujita, M. Glutathione-induced drought stress tolerance in mung bean: Coordinated roles of the antioxidant defence and methylglyoxal detoxification systems. AoB PLANTS 7, 1-18 (2015).

26. Mirzaee, M., Moieni, A. \& Ghanati, F. Effects of drought stress on the lipid peroxidation and antioxidant enzyme activities in two canola (Brassica napus L.) cultivars. Journal of Agricultural Science and Technology 15, 593-602 (2013).

27. Zhao, X. X., Huang, L. K., Zhang, X. Q., Li, Z. \& Peng, Y. Effects of heat acclimation on photosynthesis, antioxidant enzyme activities, and gene expression in orchardgrass under heat stress. Molecules 19 , 13564-13576 (2014).

28. Flexas, J. et al. Mesophyll conductance to $\mathrm{CO}_{2}$ and Rubisco as targets for improving intrinsic water use efficiency in C3 plants. Plant Cell and Environment 39, 965-982 (2016).

29. Das, A., Rushton, P. J. \& Rohila, J. S. Metabolomic profiling of soybeans (Glycine max L.) reveals the importance of sugar and nitrogen metabolism under drought and heat stress. Plants 6, 199-208 (2017).

30. Mesquita, R. O. et al. Physiological approach to decipher the drought tolerance of a soybean genotype from Brazilian savana. Plant Physiology and Biochemistry 151, 132-143 (2020).

31. Evans, J. R. \& Lawson, T. From green to gold: Agricultural revolution for food security. Journal of Experimental Botany 71, 2211-2215 (2020). 
32. Nielsen, J. \& Keasling, J. D. Engineering cellular metabolism. Cell 164, 1185-1197 (2016).

33. Sweetlove, L. J., Nielsen, J. \& Fernie, A. R. Engineering central metabolism - a grand challenge for plant biologists. Plant Journal 90, 749-763 (2017).

34. Gerganova, M., Popova, A. V., Stanoeva, D. \& Velitchkova, M. Tomato plants acclimate better to elevated temperature and high light than to treatment with each factor separately. Plant Physiology and Biochemistry 104, 234-241 (2016).

35. Birami, B. et al. Hot drought reduces the effects of elevated $\mathrm{CO}_{2}$ on tree water-use efficiency and carbon metabolism. New Phytologist 226, 1607-1621 (2020).

36. Rampino, P., Pataleo, S., Gerardi, C., Mita, G. \& Perrotta, C. Drought stress response in wheat: Physiological and molecular analysis of resistant and sensitive genotypes. Plant, Cell and Environment 29, 2143-2152 (2006).

37. Maréchaux, I. et al. Drought tolerance as predicted by leaf water potential at turgor loss point varies strongly across species within an Amazonian forest. Functional Ecology 29, 1268-1277 (2015).

38. Turner, N. C. Turgor maintenance by osmotic adjustment: 40 years of progress. Journal of Experimental Botany 69, 3223-3233 (2018).

39. Buckley, T. N. How do stomata respond to water status? New Phytologist 224, 21-36 (2019).

40. Brodribb, T. J., Sussmilch, F. \& McAdam, S. A. M. From reproduction to production, stomata are the master regulators. Plant Journal 101, $756-767$ (2020).

41. Zandalinas, S. I., Balfagón, D., Arbona, V. \& Gómez-Cadenas, A. Modulation of antioxidant defense system is associated with combined drought and heat stress tolerance in citrus. Frontiers in Plant Science 8, 1-10 (2017).

42. Goufo, P. et al. Cowpea (Vigna unguiculata L. Walp.) metabolomics: Osmoprotection as a physiological strategy for drought stress resistance and improved yield. Frontiers in Plant Science 8, 1-22 (2017).

43. Chaves, M. M. et al. Controlling stomatal aperture in semi-arid regions-The dilemma of saving water or being cool? Plant Science 251, 54-64 (2016).

44. Kumar, K. S. et al. Algal photosynthetic responses to toxic metals and herbicides assessed by chlorophyll a fluorescence. Ecotoxicology and Environmental Safety 104, 51-71 (2014).

45. Yüzbaşıoğlu, E., Dalyan, E. \& Akpınar, I. Changes in photosynthetic pigments, anthocyanin content and antioxidant enzyme activities of maize (Zea mays L.) seedlings under high temperature stress conditions. Trakya University Journal of Natural Sciences 18, 97-104 (2017).

46. Djanaguiraman, M., Boyle, D. L., Welti, R., Jagadish, S. V. K. \& Prasad, P. V. V. Decreased photosynthetic rate under high temperature in wheat is due to lipid desaturation, oxidation, acylation, and damage of organelles. BMC Plant Biology 18, 1-17 (2018).

47. Ruelland, E. \& Zachowski, A. How plants sense temperature. Environmental and Experimental Botany 69, 225-232 (2010). 
48. Zhang, L., Kondo, H., Kamikubo, H., Kataoka, M. \& Sakamoto, W. VIPP1 has a disordered C-terminal tail necessary for protecting photosynthetic membranes against stress. Plant Physiology 171, 19831995 (2016).

49. Roach, T. \& Krieger-Liszkay, A. Regulation of Photosynthetic Electron Transport and Photoinhibition. Current Protein \& Peptide Science 15, 351-362 (2014).

50. Li, Y., Song, H., Zhou, L., Xu, Z. \& Zhou, G. Tracking chlorophyll fluorescence as an indicator of drought and rewatering across the entire leaf lifespan in a maize field. Agricultural Water Management 211, 190-201 (2019).

51. Bonifacio, A. et al. Silenced rice in both cytosolic ascorbate peroxidases displays pre-acclimation to cope with oxidative stress induced by 3-aminotriazole-inhibited catalase. Journal of Plant Physiology 201, 17-27 (2016).

52. Sousa, R. H. V. et al. Impairment of peroxisomal APX and CAT activities increases protection of photosynthesis under oxidative stress. Journal of Experimental Botany 70, 627-639 (2019).

53. Souza, P. V. L. et al. Function and compensatory mechanisms among the components of the chloroplastic redox network. Critical Reviews in Plant Sciences 38, 1-28 (2019).

54. Batista, V. C. V. et al. Salicylic acid modulates primary and volatile metabolites to alleviate salt stressinduced photosynthesis impairment on medicinal plant Egletes viscosa. Environmental and Experimental Botany 167, 103870 (2019).

55. Obata, T. \& Fernie, A. R. The use of metabolomics to dissect plant responses to abiotic stresses. Cellular and Molecular Life Sciences 69, 3225-3243 (2012).

56. Araújo, W. L., Tohge, T., Ishizaki, K., Leaver, C. J. \& Fernie, A. R. Protein degradation - an alternative respiratory substrate for stressed plants. Trends in Plant Science 16, 489-498 (2011).

57. Araújo, W. L. et al. Identification of the 2-hydroxyglutarate and isovaleryl-CoA dehydrogenases as alternative electron donors linking lysine catabolism to the electron transport chain of Arabidopsis mitochondria. Plant Cell 22, 1549-1563 (2010).

58. Krasensky, J. \& Jonak, C. Drought, salt, and temperature stress-induced metabolic rearrangements and regulatory networks. Journal of Experimental Botany 63, 1593-1608 (2012).

59. Pires, M. V. et al. The influence of alternative pathways of respiration that utilize branched-chain amino acids following water shortage in Arabidopsis. Plant Cell and Environment 39, 1304-1319 (2016).

60. De Oliveira, L. F. et al. Polyamine- and amino acid-related metabolism: The roles of arginine and ornithine are associated with the embryogenic potential. Plant and Cell Physiology 59, 1084-1098 (2018).

61. Liang, X., Dickman, M. B. \& Becker, D. F. Proline biosynthesis is required for endoplasmic reticulum stress tolerance in Saccharomyces cerevisiae. Journal of Biological Chemistry 289, 27794-27806 (2014).

62. Reis, R. R. et al. Differential gene expression in response to water deficit in leaf and root tissues of soybean genotypes with contrasting tolerance profiles. Genetics and Molecular Biology 43, 1-17 
(2020).

63. Rivero, R. M. et al. The combined effect of salinity and heat reveals a specific physiological, biochemical and molecular response in tomato plants. Plant, Cell and Environment 37, 1059-1073 (2014).

64. Bowne, J. B. et al. Drought responses of leaf tissues from wheat cultivars of differing drought tolerance at the metabolite level. Molecular Plant 5, 418-429 (2012).

65. Khan, N., Bano, A., Rahman, M. A., Rathinasabapathi, B. \& Babar, M. A. UPLC-HRMS-based untargeted metabolic profiling reveals changes in chickpea (Cicer arietinum) metabolome following long-term drought stress. Plant Cell and Environment 42, 115-132 (2019).

66. Barros, J. A. S. et al. Autophagy deficiency compromises alternative pathways of respiration following energy deprivation in Arabidopsis thaliana. Plant Physiology 175, 62-76 (2017).

67. Yadav, B. S., Lahav, T., Reuveni, E., Chamovitz, D. A. \& Freilich, S. Multidimensional patterns of metabolic response in abiotic stress-induced growth of Arabidopsis thaliana. Plant Molecular Biology 92, 689-699 (2016).

68. Forchhammer, K. Glutamine signalling in bacteria. Frontiers in Bioscience 12, 358-370 (2007).

69. Kan, C. C., Chung, T. Y., Juo, Y. A. \& Hsieh, M. H. Glutamine rapidly induces the expression of key transcription factor genes involved in nitrogen and stress responses in rice roots. BMC Genomics 16 , $1-15$ (2015).

70. Xu, B. et al. GABA signalling modulates stomatal opening to enhance plant water use efficiency and drought resilience. Nature Communications 12, (2021).

71. Keunen, E., Peshev, D., Vangronsveld, J., Van Den Ende, W. \& Cuypers, A. Plant sugars are crucial players in the oxidative challenge during abiotic stress: Extending the traditional concept. Plant, Cell and Environment 36, 1242-1255 (2013).

72. Ma, L., Xue, N., Fu, X., Zhang, H. \& Li, G. Arabidopsis thaliana FAR-RED ELONGATED HYPOCOTYLS3 (FHY3) and FAR-RED-IMPAIRED RESPONSE1 (FAR1) modulate starch synthesis in response to light and sugar. New Phytologist 213, 1682-1696 (2017).

73. Merchant, A., Richter, A., Popp, M. \& Adams, M. Targeted metabolite profiling provides a functional link among eucalypt taxonomy, physiology and evolution. Phytochemistry 67, 402-408 (2006).

74. Ahn, C. H., Hossain, M. A., Lee, E., Kanth, B. K. \& Park, P. B. Increased salt and drought tolerance by Dpinitol production in transgenic Arabidopsis thaliana. Biochemical and Biophysical Research Communications 504, 315-320 (2018).

75. Thalmann, M. et al. Regulation of leaf starch degradation by abscisic acid is important for osmotic stress tolerance in plants. Plant Cell 28, 1860-1878 (2016).

76. Zanella, M. et al. $\beta$-amylase 1 (BAM1) degrades transitory starch to sustain proline biosynthesis during drought stress. Journal of Experimental Botany 67, 1819-1826 (2016).

77. do Amaral, M. N. \& Souza, G. M. The challenge to translate omics data to whole plant physiology: The context matters. Frontiers in Plant Science 8, 8-11 (2017). 
78. Neto, M. C. L., Carvalho, F. E. L., Souza, G. M. \& Silveira, J. A. G. Understanding photosynthesis in a spatial-temporal multiscale: The need for a systemic view. Theoretical and Experimental Plant Physiology 33, 113-124 (2021).

79. Bertolli, S. C., Mazzafera, P. \& Souza, G. M. Why is it so difficult to identify a single indicator of water stress in plants? A proposal for a multivariate analysis to assess emergent properties. Plant Biology $16,578-585$ (2014).

80. Mitchell, M. Complex systems: Network thinking. Artificial Intelligence 170, 1194-1212 (2006).

81. Vialet-Chabrand, S. et al. Global sensitivity analysis of onguard models identifies key hubs for transport interaction in stomatal dynamics. Plant Physiology 174, 680-688 (2017).

82. Albert, R. \& Barabási, A. L. Statistical mechanics of complex networks. Reviews of Modern Physics 74, 47-97 (2002).

83. Souza, G. M. \& Lüttge, U. Stability as a phenomenon emergent from plasticity-complexity-diversity in eco-physiology in Progress in Botany (eds. Lüttge U., Beyschlag W.), 211-239 (2015) doi:10.1007/978-3-319-08807-5_9.

84. Guimarães, P. R. The Structure of Ecological Networks across Levels of Organization. Annual Review of Ecology, Evolution, and Systematics 51, 433-460 (2020).

85. Pinheiro, F. L. \& Hartmann, D. Intermediate Levels of Network Heterogeneity Provide the Best Evolutionary Outcomes. Scientific Reports 7, 1-9 (2017).

86. Sousa, D. M. G. \& Lobato, E. Correção do solo e adubação da cultura da soja. (Embrapa - CPAC, 1996).

87. Del Longo, O. T., González, C. A., Pastori, G. M. \& Trippi, V. S. Antioxidant defences under hyperoxygenic and hyperosmotic conditions in leaves of two lines of maize with differential sensitivity to drought. Plant and Cell Physiology 34, 1023-1028 (1993).

88. Havir, E. A. \& McHale, N. A. Biochemical and Developmental Characterization of Multiple Forms of Catalase in Tobacco Leaves. Plant Physiology 84, 450-455 (1987).

89. Nakano, Y. \& Asada, K. Hydrogen peroxide is scavenged by ascorbate-specific peroxidase in spinach chloroplasts. Plant and Cell Physiology 22, 867-880 (1981).

90. Kar, M. \& Mishra, D. Catalase, peroxidase, and polyphenoloxidase activities during rice leaf senescence. Plant Physiology 57, 315-319 (1976).

91. Maehly, A. C. \& Chance, B. The assay of catalases and peroxidases. in Methods of Biochemical Analysis vol. 1, 357-424 (1954).

92. Popp, M. et al. Sample preservation for determination of organic compounds: Microwave versus freeze-drying. Journal of Experimental Botany 47, 1469-1473 (1996).

93. Basu, S. et al. Sparse network modeling and metscape-based visualization methods for the analysis of large-scale metabolomics data. Bioinformatics 33, 1545-1553 (2017).

94. Karnovsky, A. et al. Metscape 2 bioinformatics tool for the analysis and visualization of metabolomics and gene expression data. Bioinformatics 28, 373-380 (2012). 
95. Shannon, P. et al. Cytoscape: a software environment for integrated models of biomolecular interaction networks. Genome Research 13, 2498-2504 (2003).

96. Freire, F. B. S. et al. Mild reductions in guard cell sucrose synthase 2 expression leads to slower stomatal opening and decreased whole plant transpiration in Nicotiana tabacum L. Environmental and Experimental Botany 184, 104370 (2021).

97. Assenov, Y., Ramírez, F., Schelhorn, S. E. S. E., Lengauer, T. \& Albrecht, M. Computing topological parameters of biological networks. Bioinformatics 24, 282-284 (2008).

98. Chong, J. et al. MetaboAnalyst 4.0: Towards more transparent and integrative metabolomics analysis. Nucleic Acids Research 46, W486-W494 (2018).

\section{Figures}

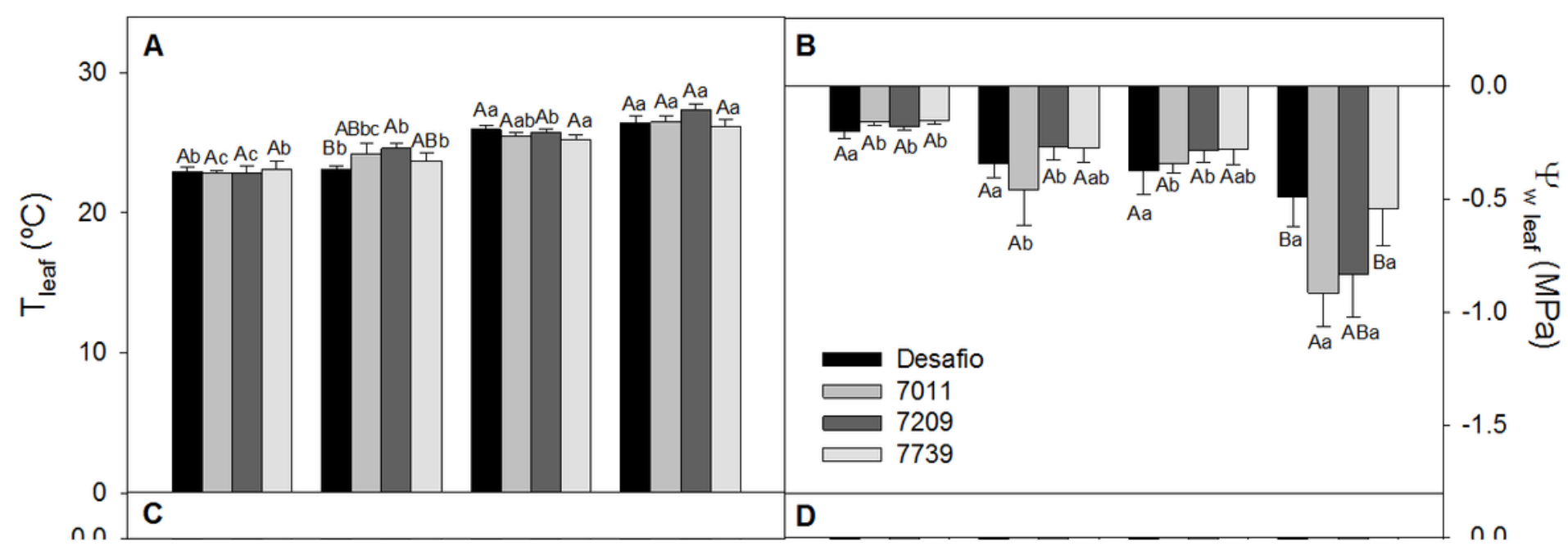

\section{Figure 1}

Leaf temperature and hydric status of soybean plants maintained for eight days under well-watered (WW; $100 \%$ holding water capacity $\mathrm{HWC}, 25^{\circ} \mathrm{C}$ ), water deficit (WD; $\left.40 \% \mathrm{HWC}, 25^{\circ} \mathrm{C}\right)$, high temperature (HT; $100 \% \mathrm{HWC}, 40^{\circ} \mathrm{C}$ ) and water deficit plus high temperature (WD+HT; $40 \% \mathrm{HWC} ; 40^{\circ} \mathrm{C}$ ) conditions. A) Leaf 
temperature ( $(\mathrm{C})$. B) Leaf water potential $\left(\Psi_{\mathrm{w}(\mathrm{am})}\right)$. C) Leaf osmotic potential $\left(\Psi_{\mathrm{s}(\text { leaf })}\right)$. D) Root osmotic potential $\left(\Psi_{\mathrm{s}(\text { root })}\right)$. Bars represent mean $\pm \operatorname{SE}(n=5)$. Means followed by the same uppercase letters compare cultivars within the same water and temperature treatment. Means followed by the same lowercase letters compare water and temperature treatments within the same cultivar, as determined by Tukey test at $5 \%$ of probability.

\section{Figure 2}

Gas exchange parameters of soybean plants maintained for eight days under well-watered (WW; $100 \%$ holding water capacity $\left.\mathrm{HWC}, 25^{\circ} \mathrm{C}\right)$, water deficit (WD; $\left.40 \% \mathrm{HWC}, 25^{\circ} \mathrm{C}\right)$, high temperature $(\mathrm{HT} ; 100 \%$ $\mathrm{HWC}, 40^{\circ} \mathrm{C}$ ) and water deficit plus high temperature (WD+HT; $\left.40 \% \mathrm{HWC} ; 40^{\circ} \mathrm{C}\right)$ conditions. A) Photosynthetic rate $\left(A, \mu \mathrm{mol} \mathrm{m} \mathrm{m}^{-2} \mathrm{~s}^{-1}\right)$. B) stomatal conductance $\left(g_{\mathrm{s}}, \mathrm{mol} \mathrm{m}^{-2} \mathrm{~s}^{-1}\right)$. C) Transpiration rate $(\mathrm{E}$, mmol m $\mathrm{m}^{-2} \mathrm{~s}^{-1}$. D) Intrinsic water-use efficiency $\left(\right.$ WUE $\left.=A / g_{\mathrm{s}}\right)$. E) Ratio of internal and external $\mathrm{CO}_{2}$ concentration $\left(C_{i} / C_{a}\right)$. F) Instantaneous carboxylation efficiency $\left(A / C_{\mathrm{i}}\right)$. Bars represent mean $\pm \mathrm{SE}(n=5)$. Means followed by the same uppercase letters compare cultivars within the same water and temperature treatment. Means followed by the same lowercase letters compare water and temperature treatments within the same cultivar, as determined by Tukey test at $5 \%$ of probability. 


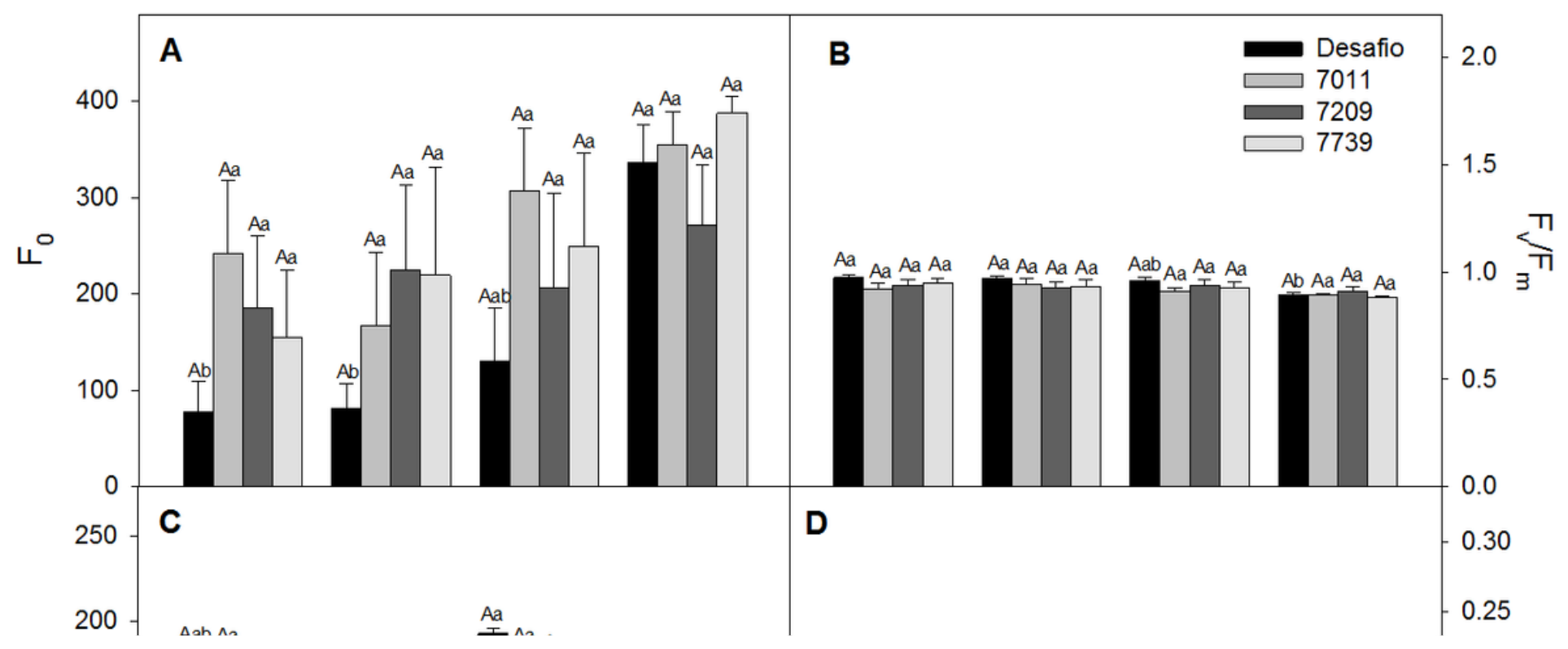

Figure 3

Photochemical parameters of soybean plants maintained for eight days under well-watered (WW; $100 \%$ holding water capacity $\left.\mathrm{HWC}, 25^{\circ} \mathrm{C}\right)$, water deficit (WD; $\left.40 \% \mathrm{HWC}, 25^{\circ} \mathrm{C}\right)$, high temperature $(\mathrm{HT} ; 100 \%$ $\left.\mathrm{HWC}, 40^{\circ} \mathrm{C}\right)$ and water deficit plus high temperature (WD+HT; $\left.40 \% \mathrm{HWC} ; 40^{\circ} \mathrm{C}\right)$ conditions. A) Minimal chlorophyll fluorescence $\left(\mathrm{F}_{0}\right)$. B) Maximum quantum yield of photosystem II (PSII) (Fv/Fm). C) Electron transport rate (ETR). D) Fraction of opened PSII reaction centers (qL). E) Effective quantum yield of PSII $\left(\mathrm{Y}_{\|}\right)$. F) Yield of non-photochemical quenching $\left(\mathrm{Y}_{\mathrm{NPQ}}\right)$. Bars represent mean $\pm \mathrm{SE}(n=5)$. Means followed 
by the same uppercase letters compare cultivars within the same water and temperature treatment. Means followed by the same lowercase letters compare water and temperature treatments within the same cultivar, as determined by Tukey test at $5 \%$ of probability.

\section{Figure 4}

Activity of antioxidant enzymes of soybean plants maintained for eight days under well-watered (WW; $100 \%$ holding water capacity HWC, $25^{\circ} \mathrm{C}$ ), water deficit (WD; $\left.40 \% \mathrm{HWC}, 25^{\circ} \mathrm{C}\right)$, high temperature (HT; $100 \% \mathrm{HWC}, 40^{\circ} \mathrm{C}$ ) and water deficit plus high temperature (WD+HT; $40 \% \mathrm{HWC} ; 40^{\circ} \mathrm{C}$ ) conditions. A) Superoxide dismutase (SOD). B) Ascorbate peroxidase (APX). C) Total peroxidase (POX). D) Catalase Bars represent mean \pm SE $(n=5)$. Means followed by the same uppercase letters compare cultivars within the same water and temperature treatment. Means followed by the same lowercase letters compare water and temperature treatments within the same cultivar, as determined by Tukey test at $5 \%$ of probability.

\section{Figure 5}

Metabolic characterization of soybean plants maintained for eight days under well-watered (WW; $100 \%$ holding water capacity $\left.\mathrm{HWC}, 25^{\circ} \mathrm{C}\right)$, water deficit (WD; $\left.40 \% \mathrm{HWC}, 25^{\circ} \mathrm{C}\right)$, high temperature $(\mathrm{HT} ; 100 \%$ $\mathrm{HWC}, 40^{\circ} \mathrm{C}$ ) and water deficit plus high temperature (WD+HT; $40 \% \mathrm{HWC} ; 40^{\circ} \mathrm{C}$ ) conditions. A) Heat map representation of the content of the metabolites identified in this study. B) Partial least squarediscriminant analysis (PLS-DA). C) Variable importance in projection (VIP) scores of the PLS-DA model. Metabolites included in this VIP score list have VIP score higher than 1, which indicates those that mostly contributed to the separation observed at the PLS-DA model. PLS-DA was carried out combining data from all genotypes. The data was normalized by using Log and Auto-scaling transformations on the MetaboAnalyst platform ${ }^{99}(n=5)$.

\section{Figure 6}

Box plots of metabolites identified as water deficit combined with high temperature (WD+HT) biomarkers. Green and red box plots indicate the relative content of metabolites found in soybean plants under well- 
watered (WW) and WD+HT conditions, respectively. Biomarkers were identified based in receiver operating characteristic (ROC) curves using Log and Auto-scaling normalized data on the MetaboAnalyst platform ${ }^{99}$. Metabolites in black and red indicate statiscal difference at $P<0.001$ and $P<0.05$, respectively.

\section{Figure 7}

Multivariate analysis combining all data of soybean plants maintained for eight days under well-watered (WW; $100 \%$ holding water capacity HWC, $25^{\circ} \mathrm{C}$ ), water deficit (WD; $\left.40 \% \mathrm{HWC}, 25^{\circ} \mathrm{C}\right)$, high temperature $(\mathrm{HT}$; $100 \% \mathrm{HWC}, 40^{\circ} \mathrm{C}$ ) and water deficit plus high temperature (WD+HT; $40 \% \mathrm{HWC} ; 40^{\circ} \mathrm{C}$ ) conditions. A) Partial least square-discriminant analysis (PLS-DA). B) Variable importance in projection (VIP) scores of the PLS-DA model. Metabolites included in the VIP score lists have VIP score higher than 1, which indicates those that mostly contributed to the separation observed at the PLS-DA model of the respective cultivar. PLS-DA was carried out combining data from all genotypes. The data was normalized by using Log and Auto-scaling transformations on the MetaboAnalyst platform ${ }^{99}(n=5)$.

\section{Figure 8}

Correlation-based networks of soybean plants maintained for eight days under A) well-watered (WW; $100 \%$ holding water capacity HWC, $25^{\circ} \mathrm{C}$ ), B) water deficit (WD; $\left.40 \% \mathrm{HWC}, 25^{\circ} \mathrm{C}\right), \mathrm{C}$ ) high temperature (HT; $100 \% \mathrm{HWC}, 40^{\circ} \mathrm{C}$ ) and $\mathrm{D}$ ) water deficit plus high temperature (WD+HT; $\left.40 \% \mathrm{HWC} ; 40^{\circ} \mathrm{C}\right)$ conditions. The networks were created combining data from anatomical, metabolic and physiological levels. The nodes are the parameters and the link is the debiased sparse partial correlation coefficient (DSPC) among then, whenever is significant $(P<0.05)$. Red and blue links correspond to positive and negative correlation among the nodes. The thickness and the intensity of the colour of the links indicate higher DSPC coefficient, in module. Bigger nodes indicate higher degree of connection. This analysis was performed using CorrelationCalculator software and the networks designed by using MetScape on CYTOSCAPE software $(n=5)$.

\section{Supplementary Files}

This is a list of supplementary files associated with this preprint. Click to download. 
- SupplementaryMaterial.docx

Page 27/27 